\title{
Constant light uncovers behavioral effects of a mutation in the schizophrenia risk gene Dtnbp1 in
} mice.

Sanjeev K. Bhardwaj ${ }^{1}$, Katarina Stojkovic ${ }^{1}$, Silke Kiessling, Lalit K. Srivastava*, Nicolas Cermakian* Douglas Mental Health University Institute, Department of psychiatry, McGill University, 6875 LaSalle Boulevard, Montreal, QC, H4H 1R3, Canada.

* Corresponding authors: Nicolas Cermakian (Tel. 514-761-6131 ext. 4936, Fax: 514-762-3034, Email: nicolas.cermakian@mcgill.ca); Lalit Srivastava (Tel. 514-761-6131 ext. 2936, Fax: 514-7623034, E-mail: lalit.srivastava@mcgill.ca).

${ }^{1}$ These authors have contributed equally to this study. 


\begin{abstract}
Various psychiatric disorders, including schizophrenia, are comorbid with sleep and circadian rhythm disruptions. To understand the links between circadian rhythms and schizophrenia, we analyzed wheel-running behavior of Sandy (Sdy) mice, which have a loss-of-function mutation in the schizophrenia risk gene Dtnbpl, and exhibit several behavioral features of schizophrenia. While rhythms of Sdy mice were mainly normal under light-dark conditions (LD) or in constant darkness (DD), they had a significantly longer free-running period under constant light (LL) compared to wildtype (WT) littermates. The mutant mice also had a higher subjective day/subjective night ratio of activity under LL, indicating lower amplitude, and a lower precision of their onsets of activity under all three lighting conditions. These observations are reminiscent of the circadian disruptions observed in schizophrenia patients. This prompted us to assess schizophrenia-relevant behavioral abnormalities in Sdy mice following alteration of the circadian rhythms by presentation of constant light. Spontaneous locomotor activity, prepulse inhibition (PPI) of acoustic startle and anxiety-like behavior were assessed under baseline LD conditions, then in LL, and then again in LD. Under LL, the Sdy mice showed significantly increased spontaneous locomotion as well as deficits in PPI compared to WT mice. Strikingly, these behavioral deficits persisted even after the mice were returned in LD conditions. While LL led to an increase in anxiety-like behavior in WT animals that was fully reversed after 3 weeks in LD, this effect was not observed in the Sdy mutants. Overall, these results suggest that Dtnbpl deficiency may lead to increased vulnerability to schizophrenia under environmental conditions where circadian rhythms are altered.
\end{abstract}

Keywords: circadian clock; light; behavior; schizophrenia; gene-environment interaction; Dtnbpl. 


\section{Introduction}

Circadian rhythms are endogenous cycles of about $24 \mathrm{~h}$ generated by a master pacemaker located in the suprachiasmatic nucleus (SCN) of the hypothalamus and by clocks located in other brain regions and in peripheral tissues [1]. At the molecular level, the circadian clock relies on self-sustained transcription-translation feedback loops involving clock genes [2]. By modulating physiological function, circadian clocks allow the organism to anticipate predictable events such as the day-night cycle and daily variations in food availability. Desynchronization between the endogenous rhythms and environmental conditions can lead to disruptions in sleep/wake behavior but also to many other health problems [3].

Many psychiatric disorders are comorbid with sleep and circadian rhythm disruptions [4]. Notably, it was reported that up to $80 \%$ of patients with schizophrenia exhibit disrupted sleep, often accompanied by unstable circadian rhythms or misalignment of the clock and the external environment [5]. Indeed, sleep and circadian disruptions significantly impair the quality of life of schizophrenic patients, who often report that the improvement of sleep is an important treatment goal [6]. Interestingly, sleep efficiency was reported to be inversely correlated with the severity of psychosis in schizophrenic patients, suggesting that amelioration of sleep and circadian rhythm disruptions could improve treatment outcome $[7,8]$.

In order to elucidate the mechanisms underlying the comorbidity of sleep and circadian disruptions and schizophrenia, several studies have recently turned to mouse models of the disorder. For example, the blind-drunk mouse, which captures certain aspects of schizophrenia, was recently found to have phase advanced and fragmented circadian locomotor activity rhythms under a 12h-light, 12h-dark cycle [9]. While the retinal input pathway and the free-running period under constant conditions seemed normal in these mice, the rhythms of two SCN outputs, vasopressin and corticosterone, also appeared to be phase-advanced, suggesting that the outputs of the SCN clock, 
rather than light input or the clock mechanism itself, are affected in this model. Other models, such as mice with Vipr2, Nrgl or Cckar gene deletions also display circadian disruptions including shortening of the free-running period, fragmentation of rest/activity rhythms and attenuation of light-induced phase shifts (reviewed in [10]). Overall, these putative models of schizophrenia emerge as important tools for further investigation on the sleep and circadian disruptions in schizophrenia.

Dtnbpl (dystrobrevin binding protein 1) has been identified as a risk gene for schizophrenia. Variations in human DTNBP1 gene were associated with schizophrenia in several genetic studies [1113]. Moreover, this genetic evidence is supported by post-mortem data showing reductions in DTNBP1 mRNA and its protein product Dysbindin-1 in the hippocampus and prefrontal cortex of schizophrenia brains $[14,15]$. The cellular functions of Dysbindin-1 are not fully understood. In various cell types, Dysbindin-1 was reported to bind to proteins such as cappuccino, muted, pallidin and snapin in a complex known as the biogenesis of lysosome-related organelle complex-1 (BLOC-1), which plays a role in protein trafficking in the endosomal-lysosomal system [16-18]. The neural and behavioral functions of Dysbindin-1 have been investigated in Sandy (Sdy) mice, which have a natural loss-offunction mutation in the Dtnbpl gene [19]. The autosomal recessive mutation in Sdy mice abolishes Dysbindin-1 protein expression, due to a $38 \mathrm{~kb}$ in-frame deletion in the gene [20]. Our group and others have previously reported that Sdy mice exhibit a number of behavioral features related to schizophrenia $[19,21]$. For example, homozygous mutant mice display reduced prepulse inhibition (PPI) of startle, altered locomotor responses to amphetamine, impaired social behavior and deficits in working, fear and object recognition memories [21-23]. In addition, Sdy mice show altered synaptic plasticity and alterations in dopamine and glutamate transmission in cortical and hippocampal regions, consistent with schizophrenia phenotype [23-26].

Here we used the Sdy mouse model to study the crosstalk between circadian disruptions and schizophrenia. We first assessed locomotor activity rhythms in homozygous mutant Sdy and wild-type (WT) mice under different lighting conditions to determine whether the SCN clock is impaired by the 
Dtnbp1 mutation. Second, we tested whether constant light conditions, which are known to alter rodent behavioral rhythms by disrupting the neuronal network within the SCN, have differential effects on the behaviors of WT and Sdy mice. More specifically, constant light increased spontaneous locomotor activity and reduced PPI in Sdy mice but not in WT mice, while it increased anxiety-like behavior in WT mice, an effect not seen in Sdy mice. Our data show genotype-specific effects of constant light conditions on wheel-running rhythms, spontaneous locomotor activity, PPI and anxiety-like behavior. 


\section{Material and methods}

\subsection{Animals}

Dtnbpl mutants, which were originally on a DBA/2J genetic background, were backcrossed to the C57BL/6J background (Jackson Laboratories) for over 10 generations. Mice for the current study were produced by breeding heterozygous parents (C57BL/6J background). The pups were genotyped using a duplex PCR procedure yielding PCR products across the deleted Dtnbpl segment in Sdy mice, as reported [22]. Adult male homozygous Sdy and WT mice were used in this study. Animal use was in accordance with the guidelines of the Canadian Council of Animal Care and was approved by McGill University Animal Care Committee.

\subsection{Experiment 1: Assessment of wheel-running activity under different lighting conditions}

\subsubsection{Protocol}

The experimental timeline is shown in Fig. 1A. The experiment was conducted in ventilated light-proof cabinets. Light in the cabinets is controlled via an external timer, ensuring precise control on the lighting schedule. WT and Sdy mice were placed individually in cages equipped with running wheels (Actimetrics, Wilmette, IL, USA), bedding and no other enrichment. Mice had ad libitum access to standard mouse chow and tap water throughout the experiment. Mice $(n=10-11$ per genotype, 9-10 months old) were subjected to a series of light conditions for 3 weeks each: $12 \mathrm{~h}$ light:12h dark cycle (LD, 200 lux), constant darkness (DD), and constant light (LL, 200 lux).

\subsubsection{Measures}

The wheel revolutions were recorded and analyzed using the ClockLab software (Actimetrics, Wilmette, IL, USA). The last 15 days of each condition were used to determine the period (tau, 
calculated using a $\chi^{2}$ periodogram and confirmed by fitting a line to the onsets of activity), the duration of the active period (alpha), the amount of activity, the subjective day/night activity ratio (where the subjective day under DD and LL conditions is the inactive period between the offset of activity and the onset of activity and the subjective night is the active period between the onset of activity and the offset of activity), the power of the Fast Fourier Transform (FFT), the cycle-to-cycle variability of the activity onsets (determined by the reciprocal of the standard deviation of individual activity onsets), the number of counts/bout of activity, the duration of activity bouts, the number of activity bouts/day (a bout is defined as a sustained period of activity; the threshold was set to 3 counts and the maximum gap set to $120 \mathrm{~min}$ for all bout parameters), and the peak rate of activity (defined as the peak number of counts/min, i.e. the most wheel rotations counted in $1 \mathrm{~min}$ for every individual bout, averaged for all bouts in each conditions). Phase angles of activity onset and offset were also calculated for the LD cycle, by subtracting the time of daily onset of activity in the evening from the time of lights off and by subtracting the time that daily activity ended in the morning from the time of lights on.

\subsection{Experiment 2: Effect of constant light on schizophrenia-relevant behaviors}

\subsubsection{Protocol}

The experimental timeline is shown in Fig. 1B. WT and Sdy mice were housed individually in running wheel cages in lightproof ventilated cabinets ( $n=9-10$ per genotype). The animals were housed individually under a $12 \mathrm{~h}$ light:12h dark cycle (LD1) for 4 weeks. Wheel-running activity was monitored during the first three weeks, and mice were then subjected to the following behavioral tasks during the fourth week, in order and separated by $48 \mathrm{~h}$ between the tests: spontaneous locomotor activity, elevated plus maze and prepulse inhibition. Mice were then subjected to constant light (LL, 200 lux) for 4 weeks, and they underwent the same behavioral tests (same order and delays) during the fourth week. Finally, the mice were subjected to LD conditions again (LD2) for 4 weeks, with a third 
identical behavioral assessment in the fourth week, to see if the behavioral abnormalities were reversed. Behavioral tests were all done during the daytime under LD1 and LD2 (between 2 and $5 \mathrm{~h}$ after the onset of light). Under LL, since the free-running period is longer than $24 \mathrm{~h}$, we ensured that the mice were at the same endogenous clock phase by doing the tests during the subjective day, similar to the testing in the LD conditions. To define the the beginning of the subjective day (CT 0) under LL, we assessed the time of onset of activity of each mouse on the day before testing (onsets being more reliable and less variable than offsets), and assumed that the subjective day was starting half a freerunning period later. Using this approach, the exact endogenous circadian time of testing was assessed for each mouse: all mice but one were tested in the subjective day, with a testing time between CT 2 and 9 for most mice. We also performed data analyses with subsets of the data set to ensure their robustness, and ensure that any differences we found was due to the effect of genotype and/or lighting condition, and not testing time. In all cases, the mice were housed in the cabinets under the same lighting conditions (LD or LL, depending on the part of the experiment) between testing sessions. Mice were 13-14 weeks old at the time of testing during LD1, 17-18 weeks old at the time of testing during LL, and 21-23 weeks old at the time of testing during LD2.

\subsubsection{Spontaneous locomotor activity}

The spontaneous locomotor activity was measured as described previously [21] using acrylic activity chambers (AccuScan Instruments, Inc., Columbus, $\mathrm{OH}, \mathrm{USA})(\mathrm{L} \times \mathrm{W} \times \mathrm{H}=17.5 \times 10 \times 26 \mathrm{~cm})$ in a dimly lit room. The chamber arenas were equipped with infrared sensors; beam breaks by the animals were used to assess locomotor activity. Data were collected using the Versamax Software (version 4.0, 2004; AccuScan Instruments, Inc.). Animals were placed in the activity boxes where their spontaneous locomotor activity was monitored during next $90 \mathrm{~min}$. The total horizontal distance traveled for the whole 90 min session was used in the analysis. 


\subsubsection{Elevated plus maze}

Anxiety-like behavior was assessed in an elevated plus maze. The apparatus (made up of wood, painted black) consists of a plus-shaped maze with two closed and two open arms, each $50 \mathrm{~cm}$ x $5 \mathrm{~cm}$ in size raised $70 \mathrm{~cm}$ above the ground. The height of the closed arm walls is $15 \mathrm{~cm}$. Animals were placed in the central arena, facing an open arm and allowed to explore the maze for $5 \mathrm{~min}$. The session was recorded with a video camera positioned above the apparatus, and the recordings were scored for the time spent in the open and the closed arms. The ratio of time spent in the open arms vs. in the closed arms was analyzed as a measure of anxiety-like behavior.

\subsubsection{Prepulse inhibition (PPI) of acoustic startle}

PPI of the acoustic startle response was measured using SR-LAB system (San Diego Instruments, San Diego, CA) as described [27]. The sound-attenuating chambers are equipped with a cylindrical Plexiglas animal enclosure and a small electric fan, which generates a $70 \mathrm{~dB}$ background noise and provides ventilation. Broadband sound pulses are presented via a speaker positioned directly above the animal. An accelerometer affixed to the animal enclosure frame detects and transduces motion resulting from the animal's startle response (whole body flinch). Sound pulse parameters are controlled using SR-LAB software, which also records the startle responses. For measuring the PPI, each animal was acclimated to the enclosure for 5 min before being tested during 32 discrete trials. In the first two trials, the magnitude of the startle response to $120 \mathrm{~dB}$ sound pulse ( $30 \mathrm{~ms}$ duration) was measured. These first two startling pulses were presented to habituate the animals to the testing procedure and were omitted from the data analysis. In the subsequent 30 trials, the startle pulse was either presented alone or 100 ms after the presentation of $30 \mathrm{~ms}$ prepulses with intensities of $6,9,12$ and $15 \mathrm{~dB}$ above the background noise. Each prepulse was presented five times and varied randomly between the trials. The animals received startle pulse alone during the other 10 trials spaced randomly. The average intertrial interval was $15 \mathrm{~s}$ (range, 5-30 s). \%PPI was calculated as: 100 - [(startle response for prepulse 
followed by pulse trials/startle response for pulse alone trials) x 100]. To assess potential differences in acoustic startle characteristics of the animals in different experimental groups, average startle response to the 10 pulse-alone trials was also analyzed separately.

\subsection{Hormone measurements and RIA}

The mice were housed singly under LD and then under LL (light set at 200 lux). Food and water were provided ad libitum. After two weeks under each lighting condition, feces samples of both WT and Sdy mice ( $\mathrm{n}=9-10$ per genotype) were collected for corticosterone measurement. Twenty-four hours before the start of sample collection, old bedding including feces was removed from the cages and replaced with a single layer of tissue to avoid contact of feces with urine. Fecal samples over the subsequent $24 \mathrm{~h}$ were then collected from each cage and stored at $-80^{\circ} \mathrm{C}$. Corticosterone metabolite extraction from each sample was performed as described [28]. Briefly, each frozen sample was thawed, dried overnight in a centrifugal evaporator, crushed into a powder-like material, and transferred to a 15 $\mathrm{mL}$ tube. Ten $\mathrm{mL}$ ethanol (100\%) was added to each sample, which was then boiled in a water bath for $20 \mathrm{~min}$. Tubes were then centrifuged for $15 \mathrm{~min}$ and the supernatant poured off into a new tube. Five $\mathrm{mL}$ ethanol was added to the pellet, the sample was vortexed for $1 \mathrm{~min}$, re-centrifuged for $15 \mathrm{~min}$, and the supernatant added to the previous $10 \mathrm{~mL}$ of extract. Supernatants were evaporated in a ventilated oven and then reconstituted with $1 \mathrm{~mL}$ methanol and stored at $-80^{\circ} \mathrm{C}$ until assay. Quantification of fecal corticoids was done using the ImmuChemTM Double Antibody Corticosterone ${ }^{125}$ I Radioimmunoassay Kit (MP Biomedicals, Orangeburg, NY). To ensure antibody binding along the linear portion of the standard curve (20 to $80 \%$ binding), fecal extracts were diluted 1:5 with diluent provided with the RIA kit. All samples were assayed in duplicate, and were run in the same experiment to exclude inter-assay variations. The standard curve and specific volumes for all solutions and controls were prepared as described in the manufacturer's protocol. 


\subsection{Statistics}

Data are presented as mean \pm SEM. Running wheel activity data were analyzed using two-way analysis of variance (ANOVA) for lighting condition and genotype, followed by Tukey's HSD posthoc test. Differences within each lighting condition were analyzed using Student's t test. The data from the behavioral tests were analyzed using two-way repeated-measures ANOVA for lighting condition and genotype, followed by Tukey's HSD post-hoc test. The whole data sets for spontaneous locomotor activity and PPI were also analyzed using a three-way ANOVA to reveal any interaction of genotype, lighting condition, and either time (for locomotion) or prepulses (for PPI). The corticosterone excretion levels were analyzed by two-way ANOVA, followed by Bonferroni post-hoc test. A p value below 0.05 was considered to indicate statistical significance. 


\section{Results}

\subsection{Effect of different lighting conditions on locomotor activity rhythms in WT and Sdy mice}

In the first experiment, WT and Sdy mice ( $\mathrm{n}=10-11$ each genotype) were subjected to different lighting conditions. The protocol is depicted in Fig. 1A. Running wheel activity was recorded for each lighting condition. Representative actograms for the two genotypes and the three lighting conditions are shown in Fig. 2A and average activity profiles for all mice over 15 days of each lighting condition are shown in Fig. 2B. The results of the analysis for various parameters are presented in Table 1. A twoway ANOVA (factors: light condition and genotype) showed that, while no main effects of genotype nor interactions were found for most parameters (there was a weak trend for the main effect of genotype for the total activity and counts/bout parameters, $\mathrm{F}_{1,57}=2.90$ and $\mathrm{F}_{1,55}=2.96$, respectively, $\mathrm{p}=0.09$ for both), there was a condition $\mathrm{x}$ genotype interaction for the period (tau) $\left(\mathrm{F}_{2,57}=8.0, \mathrm{p}<0.01\right)$, the day/night ratio $\left(\mathrm{F}_{2,57}=5.51, \mathrm{p}<0.01\right)$ and the variability of activity onsets $\left(\mathrm{F}_{2,57}=9.283, \mathrm{p}<0.001\right)$ (Table 1). We then analyzed each light condition separately (sections 3.1.1 to 3.1.3).

\subsubsection{2h light: $12 \mathrm{~h}$ dark cycle}

During the 12h-light:12h-dark condition, no significant differences were found between the two genotypes for any of the parameters tested (Fig. 2, left panels, and Table 1), except for the cycle-tocycle variability of activity onsets, which was higher for Sdy mice ( $<<0.01): 0.336 \pm 0.043 \mathrm{~h}$ in Sdy vs. $0.189 \pm 0.015 \mathrm{~h}$ in WT (Fig. 2D, left panel). Notably, the absence of a difference in the phase angles of onset and offset indicated that the ability of the circadian clock to entrain to normal lighting conditions is not disrupted in the Sdy mice. 


\subsubsection{Constant darkness}

When subjected to constant darkness, Sdy mice exhibited no differences in their locomotor activity rhythms compared to their WT counterparts (Fig. 2, center panels, and Table 1), except for the cycle-to-cycle variability of activity onsets, which was higher for Sdy mice $(\mathrm{p}<0.05): 0.520 \pm 0.065 \mathrm{~h}$ in Sdy vs. $0.369 \pm 0.022 \mathrm{~h}$ in WT (Fig. 2D, middle panel). Interestingly, the lack of effect of the Dtnbp 1 mutation on the free-running period in $\mathrm{DD}(\mathrm{p}=0.63)$ indicates that the endogenous circadian clock of Sdy mice is not significantly impaired.

\subsubsection{Constant light}

When mice were exposed to constant light (Fig. 2, right panels, and Table 1), Sdy mice were found to have a significantly longer free-running period ( $<<0.05$ ): $25.5 \mathrm{~h}$, compared to $24.9 \mathrm{~h}$ for WT mice (Fig. 2C, right panels). Moreover, the subjective day/subjective night activity ratio was almost three times higher in Sdy mice (p<0.01) (Fig. 2C, right panels). Finally, the cycle-to-cycle variability of activity onsets was higher for Sdy mice ( $\mathrm{p}<0.001)$ : $1.491 \pm 0.092 \mathrm{~h}$ in Sdy vs. $0.868 \pm 0.097 \mathrm{~h}$ in WT, a difference that was more pronounced than in LD and DD (Fig. 2D, right panel). These differences indicate that the circadian clock or the clock output pathways are more sensitive to the effects of LL in the Sdy mice. Similar observations were made under dimmer light (20 lux) in a separate experiment conducted with a new cohort of animals (data not shown).

\subsection{Effect of constant light on schizophrenia-related behaviors in Sdy mice.}

WT and Sdy mice were exposed to LD (LD1), then LL (to test the effects of LL), then LD again (LD2; to test if any effects of LL were rescued when mice were exposed again to an LD cycle). The protocol is schematized in Fig. 1B. The mice were held for 4 weeks under each condition, and different behaviors were assessed during the fourth week: spontaneous locomotor activity (see section 3.2.1), elevated plus maze (see section 3.2.2) and prepulse inhibition (see section 3.2.3). Wheel-running 
activity was continuously monitored throughout the experiment in order to ensure that all mice were well entrained to the LD cycle in LD1, that they showed the expected free-run under LL and were still rhythmic at the time of behavioral testing, and finally that in LD2 they were well entrained to the LD cycle at the time of testing (data not shown).

\subsubsection{Spontaneous locomotor activity}

We assessed the spontaneous locomotor activity of WT and Sdy mice in a novel environment. All mice displayed exploratory activity in the activity chambers, and as expected, they seemed to habituate over the course of 90 min (Fig. 3A). A three-way repeated measure ANOVA on locomotion data over time showed a significant main effect of genotype $\left(\mathrm{F}_{1,54}=18.11, \mathrm{p}<0.001\right)$ and time $\left(\mathrm{F}_{17,918}=48.52\right.$, $\mathrm{p}<0.001)$, but no significant three-way interaction $\left(\mathrm{F}_{34,918}=1.04, \mathrm{p}=0.402\right)$. Further analysis was performed on the total locomotor activity for the whole session (Fig. 3B), which showed a sustained increased activity under LL conditions specifically in Sdy mice. More specifically, a two-way ANOVA showed a significant main effect of genotype $\left(\mathrm{F}_{1,30}=14.24, \mathrm{p}<0.01\right)$ and lighting condition $\left(\mathrm{F}_{2,30}=5.40\right.$, $\mathrm{p}<0.01)$, and a trend of genotype $\mathrm{x}$ condition interaction $\left(\mathrm{F}_{2,30}=2.94, \mathrm{p}=0.068\right)$. Given the significant main effects and the strong trend for the interaction, we performed post-hoc analysis, which revealed that WT and Sdy mice showed comparable locomotor activity in the initial LD condition (LD1). However, Sdy mice showed a significant increase in locomotor activity compared to WT animals following exposure to LL $(\mathrm{p}<0.001)$. Moreover, this increase in the activity of Sdy animals following the LL phase was also significantly enhanced compared to their activity following the LD1 phase $(\mathrm{p}<0.01)$. Interestingly, exposure to the second LD phase (LD2) resulted in a partial reversal in the locomotor activity of Sdy mice as their activity was significantly reduced compared to the LL phase $(\mathrm{p}<0.05)$. However, the level of activity of Sdy mice after LD2 was still higher than for WT mice $(\mathrm{p}<0.05)$ 


\subsubsection{Elevated plus maze}

Anxiety-like behavior was assessed using the elevated plus maze test. This test showed once again a genotype-specific effect of the LL conditions, with the Sdy being more resistant to anxietypromoting effects of LL than WT mice. A two-way ANOVA on the ratio of time spent in the open arm vs. closed arm showed a significant main effect of light condition $\left(\mathrm{F}_{2,30}=5.12, \mathrm{p}<0.05\right)$ and a genotype $\mathrm{x}$ condition interaction $\left(\mathrm{F}_{2,30}=4.37, \mathrm{p}<0.05\right)$ but no effect of genotype $\left(\mathrm{F}_{1,30}=0.11, \mathrm{p}=0.75\right)$. While there was no effect of lighting condition on Sdy mice, WT mice spent significantly less time in the open arms after the LL condition compared to what was observed after the LD1 condition (post-hoc analysis, $\mathrm{p}<0.001$ ) (Fig. 4A). Also, in LL, WT animals showed a trend toward spending less time in the open arms compared to Sdy mice ( $\mathrm{p}=0.053$ ). Notably, 3 weeks of LD exposure after LL (LD2) was sufficient to rescue the effect of LL on the anxiety-like behavior of WT mice $(\mathrm{p}<0.01)$. Data on the total number of open arm entries also showed a significant main effect of light condition $\left(\mathrm{F}_{2,30}=3.59, \mathrm{p}<0.05\right)$ but no effect of genotype $\left(\mathrm{F}_{1,30}=0.003, \mathrm{p}=0.96\right)$ and a trend towards significance for genotype $\mathrm{x}$ test condition interaction $\left(\mathrm{F}_{2,30}=2.77, \mathrm{p}=0.08\right)$ (Fig. 4B).

\subsubsection{Prepulse inhibition (PPI) acoustic startle response}

PPI is a measure of sensorimotor gating where startle responses to strong auditory stimuli are attenuated when the stimuli are preceded by a weaker stimulus. As observed for the spontaneous locomotor activity, a deficit in PPI was found under LL conditions specifically in Sdy mice, and this deficit was sustained even after the mice were put back in LD. In the current experiment, the acoustic startle response was measured using four different prepulse (PP) intensities. As is typical for this paradigm, all the animals displayed an increase in \%PPI with increasing prepulse intensities (Fig. 5A). A three-way repeated measure ANOVA on \%PPI across all PP intensities showed a significant main effect of genotype $\left(\mathrm{F}_{1,135}=11.38, \mathrm{p}<0.01\right)$, light condition $\left(\mathrm{F}_{2,135}=3.79, \mathrm{p}<0.05\right)$ and $\mathrm{PP}$ intensities $\left(\mathrm{F}_{3,135}=64.05, \mathrm{p}<0.001\right)$, but no significant three-way interaction $\left(\mathrm{F}_{6,135}=1.44, \mathrm{p}=0.203\right) . \%$ PPI data with 
all PPs collapsed were then analyzed using a two-way ANOVA (Fig. 5B). This showed a significant main effect of genotype $\left(F_{1,30}=8.68, p<0.05\right)$, light condition $\left(F_{2,30}=4.49, p<0.05\right)$, and genotype $x$ light condition interaction $\left(\mathrm{F}_{2,30}=11.47, \mathrm{p}<0.001\right)$. Upon constant light exposure (LL), the Sdy mice showed a significant deficit in PPI compared to WT mice (post-hoc analysis, $\mathrm{p}<0.001$ ). The deficit in PPI in Sdy mice following LL exposure was also significantly lower than in Sdy mice following LD1 exposure $(\mathrm{p}<0.001)$ (Fig. 5B). This deficit in PPI after LL was not observed in WT mice; in fact WT mice showed a slight increase in PPI, statistically non-significant. A light-dark exposure of 3 weeks (LD2) after LL partially reversed PPI deficits in Sdy animals (Sdy-LD2 vs. Sdy-LL, p<0.05). However, \% PPI in Sdy mice was still significantly decreased compared to WT mice after LD2 ( $<<0.01)$. The baseline acoustic startle response was also analyzed by two-way ANOVA. This showed a significant main effect of light condition $\left(\mathrm{F}_{2,30}=8.35, \mathrm{p}<0.01\right)$ but no genotype $\mathrm{x}$ light condition interaction $\left(\mathrm{F}_{2,30}=0.09, \mathrm{p}=0.91\right)$ or main effect of genotype $\left(\mathrm{F}_{1,30}=2.46, \mathrm{p}=0.138\right)$, indicating that startle characteristics did not differ between the groups (data not shown).

\subsection{Corticosterone levels of WT and Sdy mice under LD and LL conditions}

We then wished to assess a possible contribution of stress to the interaction between lighting conditions and genotype. To do this, we measured corticosterone excretion (through analysis of feces collected over $24 \mathrm{~h}$ ) under both LD and LL conditions, in WT and Sdy mice. We found no difference in the levels of corticosterone excretion between WT and Sdy mice under the LD and LL conditions (Fig. 6). Fecal corticosterone excretion was previously shown to accurately reflect the corticosterone levels in the serum [29]. Thus these results indicate that the lighting conditions used in our study have no differential effects on corticosterone secretion between the two genotypes. 


\section{Discussion}

The main findings arising from our work are: 1) that the effect of exposure to constant light on the free-running period, the amplitude and the precision of locomotor activity rhythms are enhanced in Dtnbp 1 mutant mice compared to WT mice; and 2) that constant light uncovers differences in schizophrenia-related behaviors between the mutant mice and their WT littermates. There is a sustained impact of constant light on the behavior of Dtnbpl mutants, as re-introduction of the mice to a normal light-dark cycle failed to fully reverse the deficits. It is commonly recognized that the development of schizophrenia results from a number of genetic polymorphisms interacting with multiple environmental factors $[30,31]$. In this regard, our findings provide evidence for a novel gene-environment interaction in the expression of schizophrenia-relevant phenotypes in mice.

Previous research has uncovered behavioral deficits in rodents subjected to altered lighting conditions. Subjecting the animals to short light:dark cycles $(3.5 \mathrm{~h}$ light:3.5 h dark or $10 \mathrm{~h}$ light:10 h dark), such that it free-runs and light occurs at irregular times with respect to the endogenous clock, leads to altered mood and emotion-related behavior, cognition and neuronal function [32, 33]. Under a short photoperiod ( $24 \mathrm{~h}$ cycles with $8 \mathrm{~h}$ of light and $16 \mathrm{~h}$ of dark), mice exhibit increased anxiety-like and depression-like behavior, in a strain-specific manner [34]. Closer to the experimental paradigm of our study, the impact of either dim light at night or constant light on mood and cognition has been studied in different rodent species. For example, in rats, long-term (7-8 weeks) exposure to constant light leads to increased depression-like and anxiety-like behavior [35], while in mice, an LL treatment of 5-6 weeks did not modify anxiety-like behavior [36]. Other studies, either using a shorter duration of LL treatment (generally 3 weeks) or a cycle with dim light at night, also found higher depression-like behavior but, interestingly, a reduction in anxiety-like behavior [37-39]. Overall, these studies make it clear that aberrant lighting impacts on behavior and brain function. Our data add to this body of literature by comparing for the first time the impact of constant light on schizophrenia-relevant 
behaviors in WT vs. mice with a mutation in a schizophrenia risk gene, Dtnbpl. While WT mice showed no changes in general locomotion in response to LL (similar to what Fonken and colleagues found [39]), the same treatment increased the locomotion of Sdy mice.

Similarly, LL conditions reduced PPI in Sdy mice. PPI is a measure of sensorimotor gating, and reduction in PPI is considered as a reflection of poor top-down control of startle reflex by cortical and subcortical brain structures such as the prefrontal cortex and the nucleus accumbens [40]. Thus, Sdy mice after 3 weeks in LL show sensorimotor deficits. This is reminiscent of the reduced PPI observed in patients with schizophrenia [41]. Notably, our data show that the startle amplitude per se was not significantly altered by light conditions. Also, light conditions had no significant effect on the PPI of WT mice, although a weak, non-significant, increase was observed between LD1 and LD2.

Conversely, we observed an increase in anxiety-related behavior in the WT mice under LL (similar to the observations of Tapia-Osorio and colleagues in rats [35]), but Sdy mice seemed resistant to this behavioral alteration. Importantly, another new aspect of our study compared to previous research is that the behavioral alterations caused by exposure to LL in the context of the Sdy mouse genotype persist even several weeks after the mice have been returned to a regular light-dark cycle. This shows that the altered behavior is not merely an acute effect of the lighting condition but rather involves sustained changes in brain function.

In some of the previous studies, altered lighting led to behavioral abnormalities but also to increased corticosterone levels. For example, in mice under a $3.5 \mathrm{~h}$ light:3.5 h dark cycle, corticosterone peak levels are higher than on a regular LD cycle [32], while in rats under LL for extended periods of time (more than 7 weeks), the day levels become as high as the night levels [35]. This led the authors to suggest that the behavioral response to altered lighting might result from the stressful nature of the treatment and to altered corticosterone levels. To address the possibility that the effects of LL on behavior may be due to increased hypothalamus-pituitary axis activation, we measured corticosterone levels in feces from the same animals over a full $24 \mathrm{~h}$ cycle in LD and in LL. We found 
no significant effects of either lighting condition or genotype. This is consistent with other studies where corticosterone levels were either unaffected [37] or reduced [39, 42, 43] by the dim light at night or constant light. Since we measured total corticosterone excretion over a full $24 \mathrm{~h}$ period, our data do not allow us to assess whether there was an effect of the lighting conditions or genotype on the circadian rhythm of corticosterone (e.g. a phase shift). However, the data allow us to infer that the interaction of Dtnbpl genotype and lighting conditions on schizophrenia-relevant behaviors is likely not related to stress under the abnormal lighting conditions. They also indicate that the effects we have observed in this study were not due to a direct effect of light on corticosterone secretion.

Our findings raise the question of how Dysbindin-1 dysfunction could be linked to circadian rhythms deficits under constant lighting. Since disrupted rest-activity patterns mainly appear under LL conditions, it seems that the constant light exposure itself is causing or unmasking the differences observed in the mutants. Interestingly, it is known that constant light induces desynchrony between the neurons of the SCN [44], raising the possibility that the LL condition exacerbates pre-existing network connectivity impairments in the Sdy mice. Dysbindin-1 is a molecule important for intracellular trafficking in various cell types and for synaptic transmission [17, 19, 45]. Dtnbpl gene is prominently expressed in the mouse SCN [46] (http://mouse.brain-map.org/gene/show/60877), suggesting that it may have a role within this hypothalamic master clock, possibly through regulation of peptide secretion and protein trafficking. The neuronal network in the SCN relies extensively on peptide signaling [4749]. In particular, the mutation of genes encoding the $\mathrm{SCN}$-expressed vasoactive intestinal peptide (VIP) or its receptor leads to desynchrony of SCN neurons and to dampened molecular and behavioral rhythms $[48,49]$. Generally, a tight SCN neuron synchrony and consequently, robust locomotor activity rhythms rely on a tight regulation of secretory pathways. Notably, SCN proteins with a rhythmic abundance are enriched in factors important for protein trafficking and synaptic vesicle cycling, and pharmacological inhibition of these mechanisms desynchronizes SCN neurons and dampens SCN molecular rhythms [50]. In this context, it is interesting to note that other schizophrenia- 
relevant mouse models studied in the context of circadian rhythms also present mutations in genes related to protein secretion and peptide signaling (e.g. mice KO for the VIP receptor gene Vipr2, mice mutant for synaptosomal associated protein (Snap)-25) $[9,10]$. It is tempting to propose that Dysbindin-1, as part of BLOC-1 or via other protein complexes, acts on peptide signaling in the SCN, which is weakened in the context of the Dtnbpl mutation, such that constant light conditions uncover a deficit of neuronal communication. Cellular assays assessing the SCN neuronal network of Sdy mice will be required to test this hypothesis. We should point out though, that the behavioral effects of the Dtnbp 1 mutation cannot be attributed solely to the absence of the Dysbindin-1 protein. As alluded to in the Introduction, Dysbindin-1 interacts with a number of partners within the BLOC-1 complex, and the Dtnbpl mutation in Sdy mice was reported to destabilize this complex, resulting in reductions in muted and pallidin (at least in the kidney) [17]. In addition to the BLOC-1 components, Dysbindin-1 also interacts with presynaptic proteins such as snapin, a SNAP-25-binding protein. Of note, Feng et al. reported reduction of snapin in the hippocampus of Sdy mice [51]. Thus, it is possible that the effects of light conditions on the phenotype of Sdy mice could reflect disruption in SNARE-mediated presynaptic release of neurotransmitters and modulators.

As mentioned in the Introduction, the Dtnbpl mutation leads to alterations in glutamatergic, GABAergic and dopaminergic transmission. While the relationships between neurotransmitter and behavioral changes have not been clearly established in Sdy mice, with respect to dopamine, a recent report shows that adolescent blockade of D2R receptors ameliorated spine deficiency, dysconnectivity in the entorhinal-hippocampal circuit and impairment of spatial working memory in Sdy mice [52]. Two of the behaviors we studied, the spontaneous locomotor activity in a novel environment and PPI, are especially sensitive to mesolimbic dopamine $[53,54]$. Therefore, one possibility is that constant light produces abnormalities in Sdy mice through dopaminergic mechanisms. However, nondopaminergic mechanisms, e.g., serotonergic, adrenergic and glutamatergic, have also been implicated in these behaviors [54-56] as well as in the performance in the elevated plus maze task [57, 58]. It is 
notable that the circadian system interacts with different neurotransmitter systems. In particular, the dopaminergic system is showing circadian regulation at different levels [59], and clock transcription factors were shown to regulate the expression of enzymes important for dopamine production. Indeed, knock-out of the nuclear receptor REV-ERB $\alpha$ and a dominant negative mutation of CLOCK protein both led to increased tyrosine hydroxylase expression and dopamine transmission, as well as an alteration of related behaviors [60-62]. The molecular clock also controls the expression of the Monoamine oxidase $A$ gene [63]. Interestingly, the regulation also occurs in the other direction, as dopamine regulates clock mechanisms via the D2R receptor [64, 65], and dopamine depletion in the rat forebrain disrupts clock gene expression and wheel-running activity rhythms [66]. Interestingly, dopamine depletion in the brain of monkeys led to a deterioration of their locomotor rhythms in LD and a much higher sensitivity of the effects of LL [67]. Further studies examining neurotransmitter levels and activity in our paradigm are needed to resolve these questions.

Although it is well known that sleep and circadian disturbances are often associated with schizophrenia $[4,5]$, little is known about the causal relationships between these alterations and the etiology of the disease. In particular, it is of high medical and social interest to know whether altered behavioral rhythms may lead to a worsening of schizophrenia symptoms. Here, we have used a mouse genetic model to uncover a two-way relationship between circadian rhythms and schizophreniarelevant behaviors. On one hand, mutation in a gene with altered expression in schizophrenia patients leads to circadian disturbances in mouse running-wheel behavior. On the other hand, lighting conditions that induce circadian disturbances uncover schizophrenia-like behaviors, effects which are long-lasting even weeks after the end of the altered lighting conditions. Alterations of circadian rhythms are seen in shift workers, who account for $15-30 \%$ of the workforce in industrialized countries [68]. More broadly, the modern lifestyle involves irregular schedules of activity and light exposure for a large proportion of the population. Our work suggests that such environmental or lifestyle-driven 
alterations in behavioral and physiological rhythms could act as a predisposing factor for schizophrenia. 


\section{Acknowledgements}

We thank all members of N.C. and L.S.’s laboratories for discussion, and G. Dubeau-Laramée et H.Y. Zhang for technical help. This work was supported by grants from the Canadian Institutes of Health Research (MOP-81123, to L.S.) and the Natural Sciences and Engineering Research Council (RGPIN 249731-12, to N.C.). K.S. was supported by a fellowship from McGill Faculty of Medicine and N.C. by a salary award from the Fonds de Recherche du Québec — Santé. 


\section{Figure Legends}

Fig. 1. Experimental design. (A) In Experiment 1, WT and Dtnbpl mutant (Sdy) mice were subjected to different lighting conditions for 3 weeks each and various parameters of running wheel locomotor activity were evaluated in the last 15 days of each condition. Data are shown in Fig. 2. (B) In Experiment 2, WT and Sdy mice were exposed to a light:dark cycle (LD1), then to constant light (LL), and then to LD again (LD2), 4 weeks for each condition. Behavioral tests were performed in the fourth week of each lighting condition in the following order: spontaneous locomotor activity, elevated plus maze (EPM) and prepulse inhibition (PPI). Data are shown in Figs 3-5.

Fig. 2. Parameters of locomotor activity rhythms of WT and Dtnbpl mutant (Sdy) mice under different lighting conditions: 12h light:12h dark cycle (LD) (left panels), constant darkness (DD) (center panels) and constant light (LL) (right panels). (A) Representative actograms for the three lighting conditions and the two genotypes. Only the last 15 days of each condition, which were used to determine the rhythm parameters, are shown. (B) Activity profiles, averaged for all mice, over the 15 days (black line, WT; grey line, Sdy). (C) Period (tau) and day/night (or subjective day/subjective night in DD and LL) activity ratio. (D) Cycle-to-cycle variability of the activity onsets. Student's t test: *** $\mathrm{p}<0.001, * *$ $\mathrm{p}<0.01, * \mathrm{p}<0.05$

Fig. 3. Spontaneous locomotor activity in WT and Dtnbpl mutant (Sdy) mice following exposure to different lighting conditions. The test was performed during the daytime under LD1 and LD2 (between 2 and $5 \mathrm{~h}$ after the onset of light) and generally during the subjective day (rest period) under LL. (A) Time course of locomotor activity over $90 \mathrm{~min}$. (B) Total distance traveled during the whole 90-min session. Two-way ANOVA for genotype $\mathrm{x}$ condition interaction, $\mathrm{F}_{2,30}=2.94, \mathrm{p}=0.068$ (trend); main 
effect of genotype, $F_{1,30}=14.24, p<0.01$; main effect of condition, $F_{2,30}=5.40, p<0.01$. Post-hoc analysis: $* * * \mathrm{p}<0.001, * * \mathrm{p}<0.01, * \mathrm{p}<0.05$.

Fig. 4. Anxiety-like behavior assessed by elevated plus maze test in WT and Dtnbpl mutant (Sdy) mice following exposure to different lighting conditions. The test was performed during the daytime under LD1 and LD2 (between 2 and $5 \mathrm{~h}$ after the onset of light) and generally during the subjective day (rest period) under LL. (A) Ratio of the time spent in open arms vs. closed arms. Two-way ANOVA for genotype $x$ condition interaction, $F_{2,30}=4.37$, $p<0.05$; main effect of condition, $F_{2,30}=5.12$, $p<0.05$ (no main effect of genotype, $\mathrm{F}_{1,30}=0.11, \mathrm{p}=0.75$ ). Post-hoc analysis: $* * \mathrm{p}<0.01,{ }^{*} \mathrm{p}<0.05$. (B) Number of entries in the open arms. Two-way ANOVA for genotype $x$ condition interaction, $F_{2,30}=2.77, p=0.08$ (trend); main effect of condition, $\mathrm{F}_{2,30}=3.59, \mathrm{p}<0.05$ (no main effect of genotype, $\mathrm{F}_{1,30}=0.003$, $\mathrm{p}=0.96$ ).

Fig. 5. Prepulse inhibition (PPI) of acoustic startle response in WT and Dtnbpl mutant (Sdy) mice following exposure to different lighting conditions. The test was performed during the daytime under LD1 and LD2 (between 2 and $5 \mathrm{~h}$ after the onset of light) and generally during the subjective day (rest period) under LL. (A) Prepulse inhibition, as a function of prepulse intensities (PPs). (B) Prepulse inhibition collapsed across all PP levels. Two-way ANOVA for genotype x condition interaction, $\mathrm{F}_{2,30}=11.47, \mathrm{p}<0.001 ;$ main effect of genotype, $\mathrm{F}_{1,30}=8.68, \mathrm{p}<0.05$; main effect of condition, $\mathrm{F}_{2,30}=4.49$, $\mathrm{p}<0.05$. Post-hoc analysis: $* * * \mathrm{p}<0.001, * * \mathrm{p}<0.01$

Fig. 6. Corticosterone excretion in WT and Dtnbpl mutant (Sdy) mice during different lighting conditions. Samples were collected over 24 h under a light:dark cycle (LD) and constant light (LL). Two-way ANOVA for genotype $\mathrm{x}$ condition, $\mathrm{F}_{1,35}=0.0105, \mathrm{p}=0.92$; main effect of genotype, $\mathrm{F}_{1,35}=3.37$, $\mathrm{p}=0.07$; main effect of condition, $\mathrm{F}_{1,35}=0.93, \mathrm{p}=0.34$. 


\section{References}

[1] Dibner C, Schibler U, Albrecht U. The mammalian circadian timing system: organization and coordination of central and peripheral clocks. Annu Rev Physiol. 2010;72:517-49.

[2] Duguay D, Cermakian N. The crosstalk between physiology and circadian clock proteins. Chronobiol Int. 2009;26:1479-513.

[3] Evans JA, Davidson AJ. Health consequences of circadian disruption in humans and animal models. Progress in molecular biology and translational science. 2013;119:283-323.

[4] Cuesta M, Cermakian N, Boivin DB. Circadian clock genes and psychiatric disorders. In: P. Shaw MT, M. Thorpy, editor. The genetic basis of sleep and sleep disorders: University of Cambridge Press; 2013. p. 351-64.

[5] Wulff K, Dijk DJ, Middleton B, Foster RG, Joyce EM. Sleep and circadian rhythm disruption in schizophrenia. The British journal of psychiatry : the journal of mental science. 2012;200:308-16.

[6] Auslander LA, Jeste DV. Perceptions of problems and needs for service among middle-aged and elderly outpatients with schizophrenia and related psychotic disorders. Community Ment Health J. 2002;38:391-402.

[7] Boivin DB. Influence of sleep-wake and circadian rhythm disturbances in psychiatric disorders. J Psychiatry Neurosci. 2000;25:446-58.

[8] Tandon R, Shipley JE, Taylor S, Greden JF, Eiser A, DeQuardo J, et al. Electroencephalographic sleep abnormalities in schizophrenia. Relationship to positive/negative symptoms and prior neuroleptic treatment. Arch Gen Psychiatry. 1992;49:185-94.

[9] Oliver PL, Sobczyk MV, Maywood ES, Edwards B, Lee S, Livieratos A, et al. Disrupted circadian rhythms in a mouse model of schizophrenia. Current biology : CB. 2012;22:314-9. 
[10] Pritchett D, Wulff K, Oliver PL, Bannerman DM, Davies KE, Harrison PJ, et al. Evaluating the links between schizophrenia and sleep and circadian rhythm disruption. J Neural Transm. 2012;119:1061-75.

[11] Schwab SG, Knapp M, Mondabon S, Hallmayer J, Borrmann-Hassenbach M, Albus M, et al. Support for association of schizophrenia with genetic variation in the $6 \mathrm{p} 22.3$ gene, dysbindin, in sib-pair families with linkage and in an additional sample of triad families. AmJ HumGenet. $2003 ; 72: 185-90$

[12] Straub RE, Jiang Y, MacLean CJ, Ma Y, Webb BT, Myakishev MV, et al. Genetic variation in the 6p22.3 gene DTNBP1, the human ortholog of the mouse dysbindin gene, is associated with schizophrenia. AmJ HumGenet. 2002;71:337-48.

[13] Williams NM, Preece A, Morris DW, Spurlock G, Bray NJ, Stephens M, et al. Identification in 2 independent samples of a novel schizophrenia risk haplotype of the dystrobrevin binding protein gene (DTNBP1). Arch Gen Psychiatry. 2004;61:336-44.

[14] Talbot K, Eidem WL, Tinsley CL, Benson MA, Thompson EW, Smith RJ, et al. Dysbindin-1 is reduced in intrinsic, glutamatergic terminals of the hippocampal formation in schizophrenia. J ClinInvest. 2004;113:1353-63.

[15] Weickert CS, Straub RE, McClintock BW, Matsumoto M, Hashimoto R, Hyde TM, et al. Human dysbindin (DTNBP1) gene expression in normal brain and in schizophrenic prefrontal cortex and midbrain. Arch Gen Psychiatry. 2004;61:544-55.

[16] Ghiani CA, Starcevic M, Rodriguez-Fernandez IA, Nazarian R, Cheli VT, Chan LN, et al. The dysbindin-containing complex (BLOC-1) in brain: developmental regulation, interaction with SNARE proteins and role in neurite outgrowth. Mol Psychiatry. 2010;15:115, 204-15.

[17] Li W, Zhang Q, Oiso N, Novak EK, Gautam R, O'Brien EP, et al. Hermansky-Pudlak syndrome type 7 (HPS-7) results from mutant dysbindin, a member of the biogenesis of lysosome-related organelles complex 1 (BLOC-1). NatGenet. 2003;35:84-9. 
[18] Starcevic M, Dell'Angelica EC. Identification of snapin and three novel proteins (BLOS1, BLOS2, and BLOS3/reduced pigmentation) as subunits of biogenesis of lysosome-related organelles complex-1 (BLOC-1). J Biol Chem. 2004;279:28393-401.

[19] Talbot K. The sandy (sdy) mouse: a dysbindin-1 mutant relevant to schizophrenia research. Progress in brain research. 2009;179:87-94.

[20] Swank RT, Sweet HO, Davisson MT, Reddington M, Novak EK. Sandy: a new mouse model for platelet storage pool deficiency. GenetRes. 1991;58:51-62.

[21] Bhardwaj SK, Baharnoori M, Sharif-Askari B, Kamath A, Williams S, Srivastava LK. Behavioral characterization of dysbindin-1 deficient sandy mice. Behav Brain Res. 2009;197:435-41.

[22] Cox MM, Tucker AM, Tang J, Talbot K, Richer DC, Yeh L, et al. Neurobehavioral abnormalities in the dysbindin-1 mutant, sandy, on a C57BL/6J genetic background. Genes Brain Behav. 2009;8:390-7.

[23] Papaleo F, Yang F, Garcia S, Chen J, Lu B, Crawley JN, et al. Dysbindin-1 modulates prefrontal cortical activity and schizophrenia-like behaviors via dopamine/D2 pathways. Mol Psychiatry. 2010;DOI:10.1038/mp.2010.106.

[24] Jentsch JD, Trantham-Davidson H, Jairl C, Tinsley M, Cannon TD, Lavin A. Dysbindin modulates prefrontal cortical glutamatergic circuits and working memory function in mice. Neuropsychopharmacology. 2009;34:2601-8.

[25] Ji Y, Yang F, Papaleo F, Wang HX, Gao WJ, Weinberger DR, et al. Role of dysbindin in dopamine receptor trafficking and cortical GABA function. ProcNatlAcadSciUSA. 2009;106:19593-8.

[26] Karlsgodt KH, Robleto K, Trantham-Davidson H, Jairl C, Cannon TD, Lavin A, et al. Reduced dysbindin expression mediates N-methyl-D-aspartate receptor hypofunction and impaired working memory performance. BiolPsychiatry. 2011;69:28-34. 
[27] Kamath A, Al-Khairi I, Bhardwaj S, Srivastava LK. Enhanced alpha1 adrenergic sensitivity in sensorimotor gating deficits in neonatal ventral hippocampus-lesioned rats. The international journal of neuropsychopharmacology / official scientific journal of the Collegium Internationale Neuropsychopharmacologicum. 2008;11:1085-96.

[28] Cavigelli SA, Monfort SL, Whitney TK, Mechref YS, Novotny M, McClintock MK. Frequent serial fecal corticoid measures from rats reflect circadian and ovarian corticosterone rhythms. The Journal of endocrinology. 2005;184:153-63.

[29] Abraham D, Dallmann R, Steinlechner S, Albrecht U, Eichele G, Oster H. Restoration of circadian rhythmicity in circadian clock-deficient mice in constant light. J Biol Rhythms. 2006;21:169-76.

[30] Tandon R, Keshavan MS, Nasrallah HA. Schizophrenia, "just the facts" what we know in 2008. 2. Epidemiology and etiology. Schizophr Res. 2008;102:1-18.

[31] Van Os J, Rutten BP, Poulton R. Gene-environment interactions in schizophrenia: review of epidemiological findings and future directions. Schizophrenia bulletin. 2008;34:1066-82.

[32] LeGates TA, Altimus CM, Wang H, Lee HK, Yang S, Zhao H, et al. Aberrant light directly impairs mood and learning through melanopsin-expressing neurons. Nature. 2012;491:594-8.

[33] Karatsoreos IN, Bhagat S, Bloss EB, Morrison JH, McEwen BS. Disruption of circadian clocks has ramifications for metabolism, brain, and behavior. Proceedings of the National Academy of Sciences of the United States of America. 2011;108:1657-62.

[34] Otsuka T, Kawai M, Togo Y, Goda R, Kawase T, Matsuo H, et al. Photoperiodic responses of depression-like behavior, the brain serotonergic system, and peripheral metabolism in laboratory mice. Psychoneuroendocrinology. 2014;40:37-47.

[35] Tapia-Osorio A, Salgado-Delgado R, Angeles-Castellanos M, Escobar C. Disruption of circadian rhythms due to chronic constant light leads to depressive and anxiety-like behaviors in the rat. Behav Brain Res. 2013;252C:1-9. 
[36] Castro JP, Frussa-Filho R, Fukushiro DF, Chinen CC, Abilio VC, Silva RH. Effects of long-term continuous exposure to light on memory and anxiety in mice. Physiology \& behavior. 2005;86:218-23.

[37] Bedrosian TA, Fonken LK, Walton JC, Haim A, Nelson RJ. Dim light at night provokes depression-like behaviors and reduces CA1 dendritic spine density in female hamsters. Psychoneuroendocrinology. 2011;36:1062-9.

[38] Ma WP, Cao J, Tian M, Cui MH, Han HL, Yang YX, et al. Exposure to chronic constant light impairs spatial memory and influences long-term depression in rats. Neuroscience research. 2007;59:224-30.

[39] Fonken LK, Finy MS, Walton JC, Weil ZM, Workman JL, Ross J, et al. Influence of light at night on murine anxiety- and depressive-like responses. Behav Brain Res. 2009;205:349-54.

[40] Swerdlow NR, Geyer MA, Braff DL. Neural circuit regulation of prepulse inhibition of startle in the rat: current knowledge and future challenges. Psychopharmacology (Berl). 2001;156:194-215.

[41] Braff DL. Prepulse inhibition of the startle reflex: a window on the brain in schizophrenia. Current topics in behavioral neurosciences. 2010;4:349-71.

[42] Coomans CP, van den Berg SA, Houben T, van Klinken JB, van den Berg R, Pronk AC, et al. Detrimental effects of constant light exposure and high-fat diet on circadian energy metabolism and insulin sensitivity. FASEB J. 2013;27:1721-32.

[43] Claustrat B, Valatx JL, Harthe C, Brun J. Effect of constant light on prolactin and corticosterone rhythms evaluated using a noninvasive urine sampling protocol in the rat. Hormone and metabolic research $=$ Hormon- und Stoffwechselforschung $=$ Hormones et metabolisme. 2008;40:398-403.

[44] Ohta H, Yamazaki S, McMahon DG. Constant light desynchronizes mammalian clock neurons. Nat Neurosci. 2005;8:267-9. 
[45] Newell-Litwa K, Salazar G, Smith Y, Faundez V. Roles of BLOC-1 and Adaptor Protein-3 Complexes in Cargo Sorting to Synaptic Vesicles. Molecular Biology of the Cell. 2009;20:144153.

[46] Lein ES, Hawrylycz MJ, Ao N, Ayres M, Bensinger A, Bernard A, et al. Genome-wide atlas of gene expression in the adult mouse brain. Nature. 2007;445:168-76.

[47] Hastings MH, Brancaccio M, Maywood ES. Circadian pacemaking in cells and circuits of the suprachiasmatic nucleus. Journal of neuroendocrinology. 2014;26:2-10.

[48] Maywood ES, Reddy AB, Wong GK, O'Neill JS, O'Brien JA, McMahon DG, et al. Synchronization and maintenance of timekeeping in suprachiasmatic circadian clock cells by neuropeptidergic signaling. Current biology : CB. 2006;16:599-605.

[49] Aton SJ, Colwell CS, Harmar AJ, Waschek J, Herzog ED. Vasoactive intestinal polypeptide mediates circadian rhythmicity and synchrony in mammalian clock neurons. Nat Neurosci. 2005;8:476-83.

[50] Deery MJ, Maywood ES, Chesham JE, Sladek M, Karp NA, Green EW, et al. Proteomic analysis reveals the role of synaptic vesicle cycling in sustaining the suprachiasmatic circadian clock. Current biology : CB. 2009;19:2031-6.

[51] Feng YQ, Zhou ZY, He X, Wang H, Guo XL, Hao CJ, et al. Dysbindin deficiency in sandy mice causes reduction of snapin and displays behaviors related to schizophrenia. Schizophr Res. 2008;106:218-28.

[52] Jia JM, Zhao J, Hu Z, Lindberg D, Li Z. Age-dependent regulation of synaptic connections by dopamine D2 receptors. Nat Neurosci. 2013;16:1627-36.

[53] Doherty JM, Masten VL, Powell SB, Ralph RJ, Klamer D, Low MJ, et al. Contributions of dopamine D1, D2, and D3 receptor subtypes to the disruptive effects of cocaine on prepulse inhibition in mice. Neuropsychopharmacology. 2008;33:2648-56. 
[54] Hooks MS, Kalivas PW. Involvement of dopamine and excitatory amino acid transmission in novelty-induced motor activity. J PharmacolExpTher. 1994;269:976-88.

[55] Maier W, Mossner R, Quednow BB, Wagner M, Hurlemann R. From genes to psychoses and back: the role of the 5HT2alpha-receptor and prepulse inhibition in schizophrenia. EurArch Psychiatry ClinNeurosci. 2008;258 Suppl 5:40-3.

[56] Pietraszek M, Gravius A, Sch\%ofer D, Weil T, Trifanova D, Danysz W. mGluR5, but not mGluR1, antagonist modifies MK-801-induced locomotor activity and deficit of prepulse inhibition. Neuropharmacology. 2005;49:73-85.

[57] Alves SH, Pinheiro G, Motta V, Landeira-Fernandez J, Cruz AP. Anxiogenic effects in the rat elevated plus-maze of 5-HT(2C) agonists into ventral but not dorsal hippocampus. BehavPharmacol. 2004;15:37-43.

[58] Linden AM, Shannon H, Baez M, Yu JL, Koester A, Schoepp DD. Anxiolytic-like activity of the mGLU2/3 receptor agonist LY354740 in the elevated plus maze test is disrupted in metabotropic glutamate receptor 2 and 3 knock-out mice. Psychopharmacology (Berl). 2005;179:284-91.

[59] Mendoza J, Challet E. Circadian insights into dopamine mechanisms. Neuroscience. 2014.

[60] McClung CA, Sidiropoulou K, Vitaterna M, Takahashi JS, White FJ, Cooper DC, et al. Regulation of dopaminergic transmission and cocaine reward by the Clock gene. Proceedings of the National Academy of Sciences of the United States of America. 2005;102:9377-81.

[61] Jager J, O'Brien WT, Manlove J, Krizman EN, Fang B, Gerhart-Hines Z, et al. Behavioral changes and dopaminergic dysregulation in mice lacking the nuclear receptor Rev-erbalpha. Molecular endocrinology. 2014;28:490-8.

[62] Chung S, Lee EJ, Yun S, Choe HK, Park SB, Son HJ, et al. Impact of circadian nuclear receptor REV-ERBalpha on midbrain dopamine production and mood regulation. Cell. 2014;157:858-68. 
[63] Hampp G, Ripperger JA, Houben T, Schmutz I, Blex C, Perreau-Lenz S, et al. Regulation of monoamine oxidase A by circadian-clock components implies clock influence on mood. Current biology : CB. 2008;18:678-83.

[64] Yujnovsky I, Hirayama J, Doi M, Borrelli E, Sassone-Corsi P. Signaling mediated by the dopamine D2 receptor potentiates circadian regulation by CLOCK:BMAL1. Proceedings of the National Academy of Sciences of the United States of America. 2006;103:6386-91.

[65] Hood S, Cassidy P, Cossette MP, Weigl Y, Verwey M, Robinson B, et al. Endogenous dopamine regulates the rhythm of expression of the clock protein PER2 in the rat dorsal striatum via daily activation of D2 dopamine receptors. The Journal of neuroscience : the official journal of the Society for Neuroscience. 2010;30:14046-58.

[66] Gravotta L, Gavrila AM, Hood S, Amir S. Global depletion of dopamine using intracerebroventricular 6-hydroxydopamine injection disrupts normal circadian wheel-running patterns and PERIOD2 expression in the rat forebrain. Journal of molecular neuroscience : MN. 2011;45:162-71.

[67] Fifel K, Vezoli J, Dzahini K, Claustrat B, Leviel V, Kennedy H, et al. Alteration of daily and circadian rhythms following dopamine depletion in MPTP treated non-human primates. PloS one. 2014;9:e86240.

[68] Boivin DB, Tremblay GM, James FO. Working on atypical schedules. Sleep Med. 2007;8:578-89. 
Figure 1

A

Animals born, weaned, genotyped and group housed

in enriched environment

Animals housed individually into running wheel cages

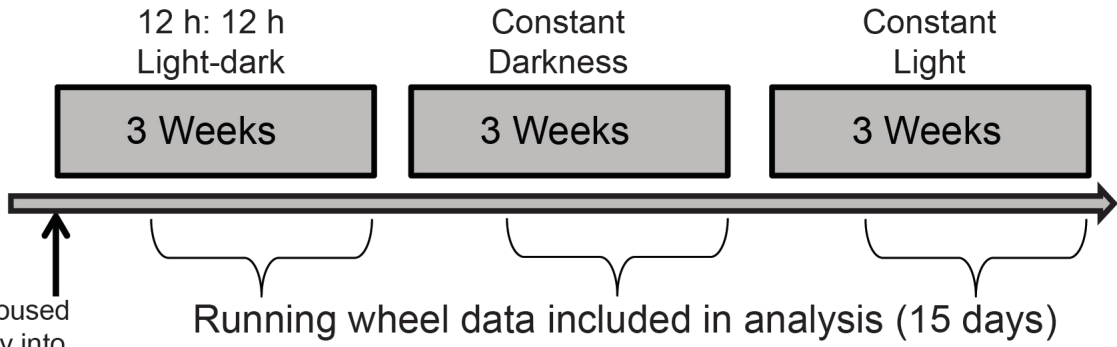

B

$12 \mathrm{~h}: 12 \mathrm{~h}$

Light-dark (LD1)

Animals born, weaned, genotyped and group housed in enriched environment
Animals housed individually into running wheel cages

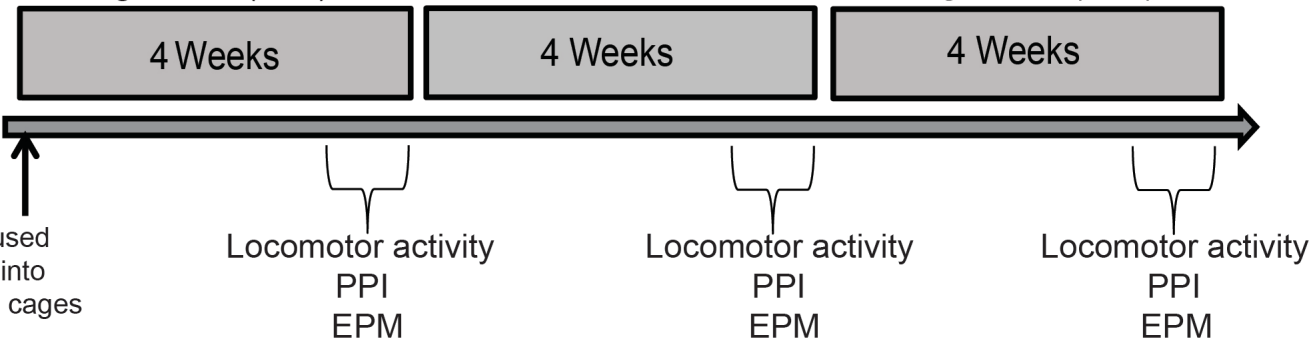

4 Weeks

Light (LL)

$12 \mathrm{~h}: 12 \mathrm{~h}$

Light-dark (LD2)

4 Weeks 
Figure 2

A

LD

DD

LL
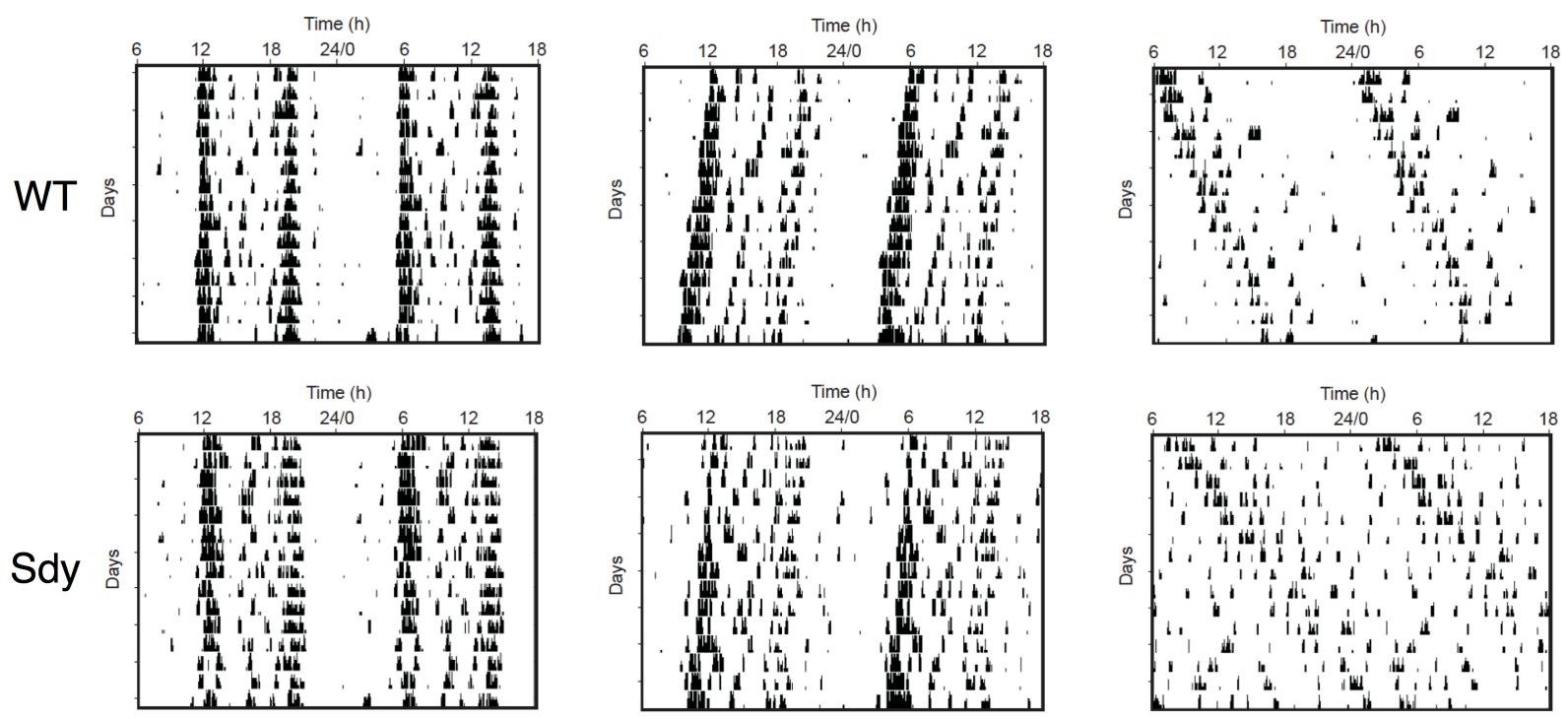

B
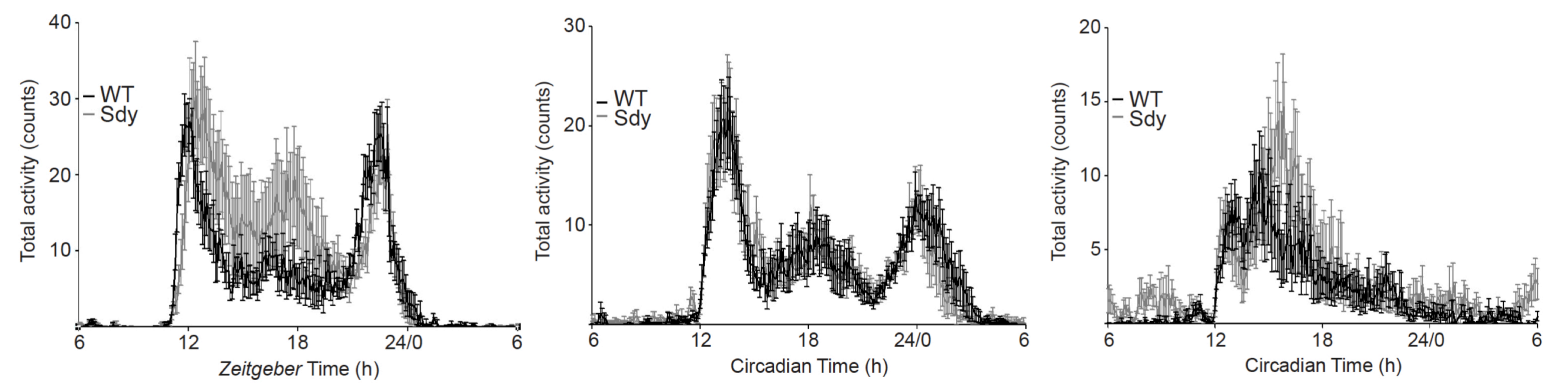

C
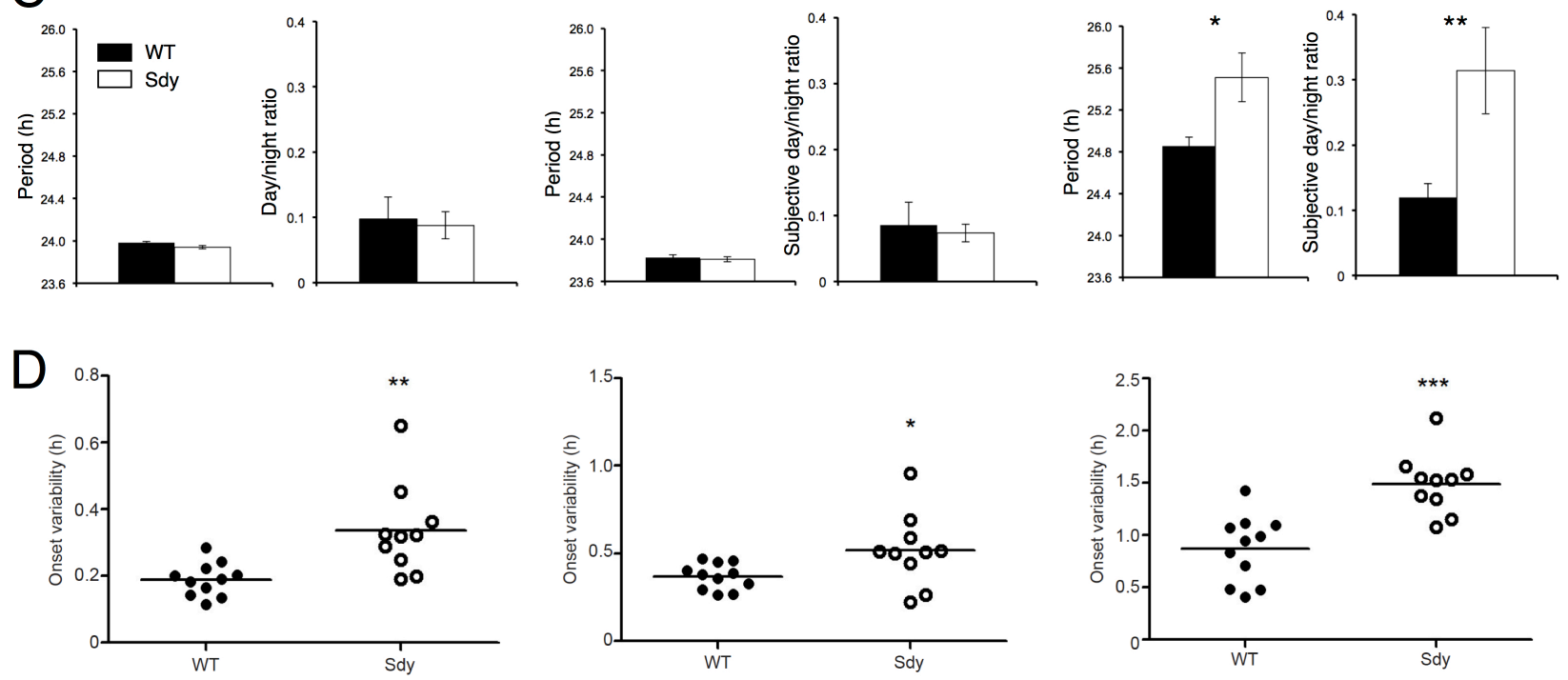
Figure 3
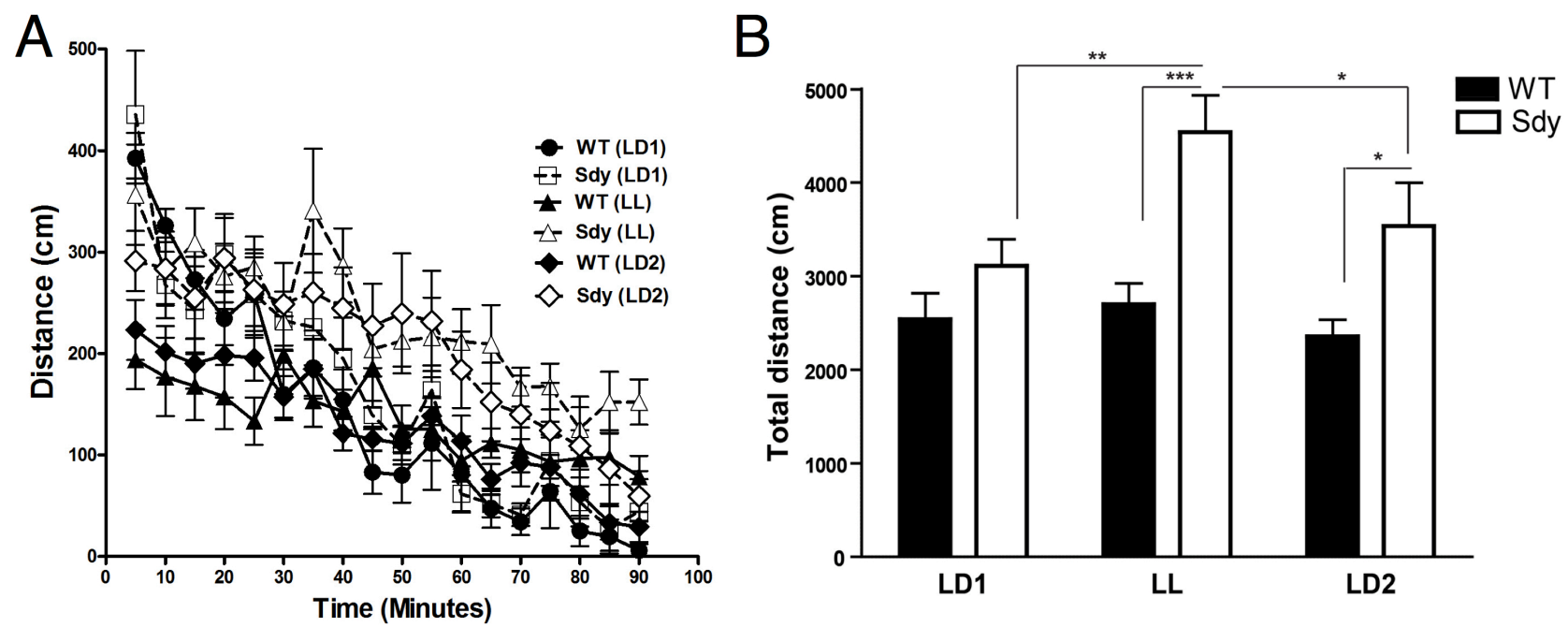
Figure 4
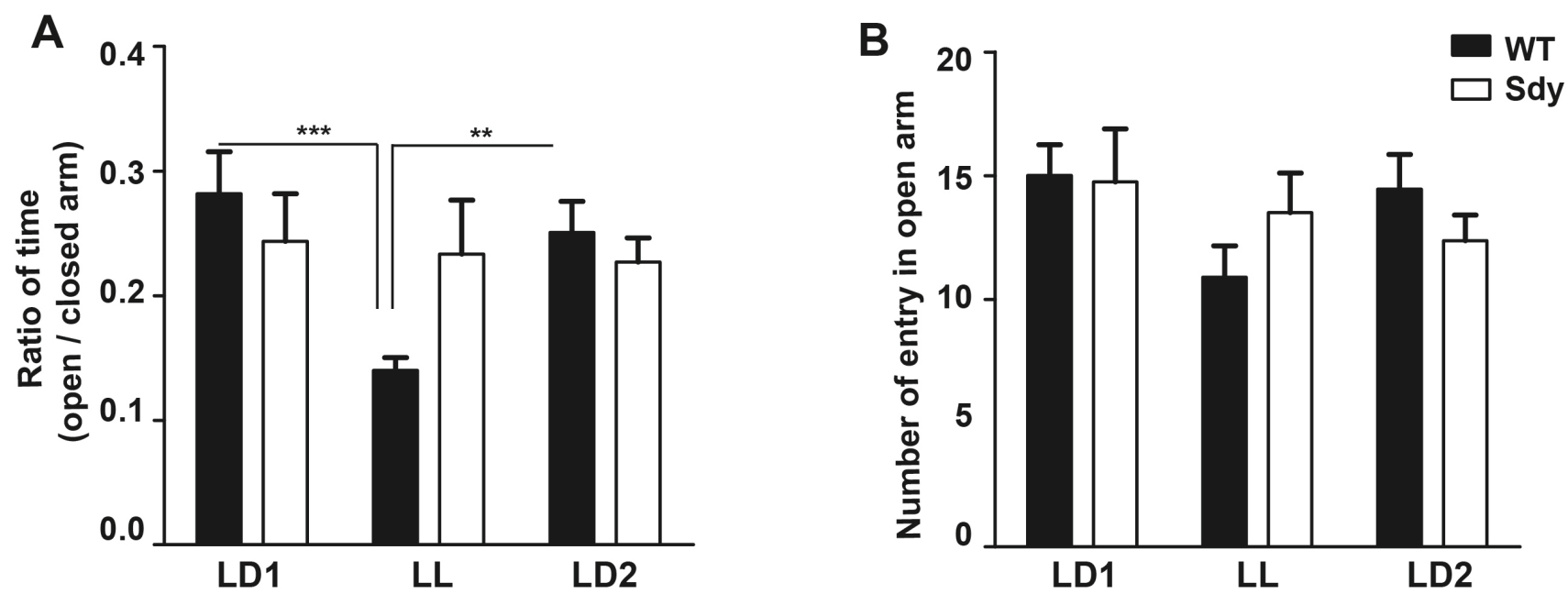
Figure 5
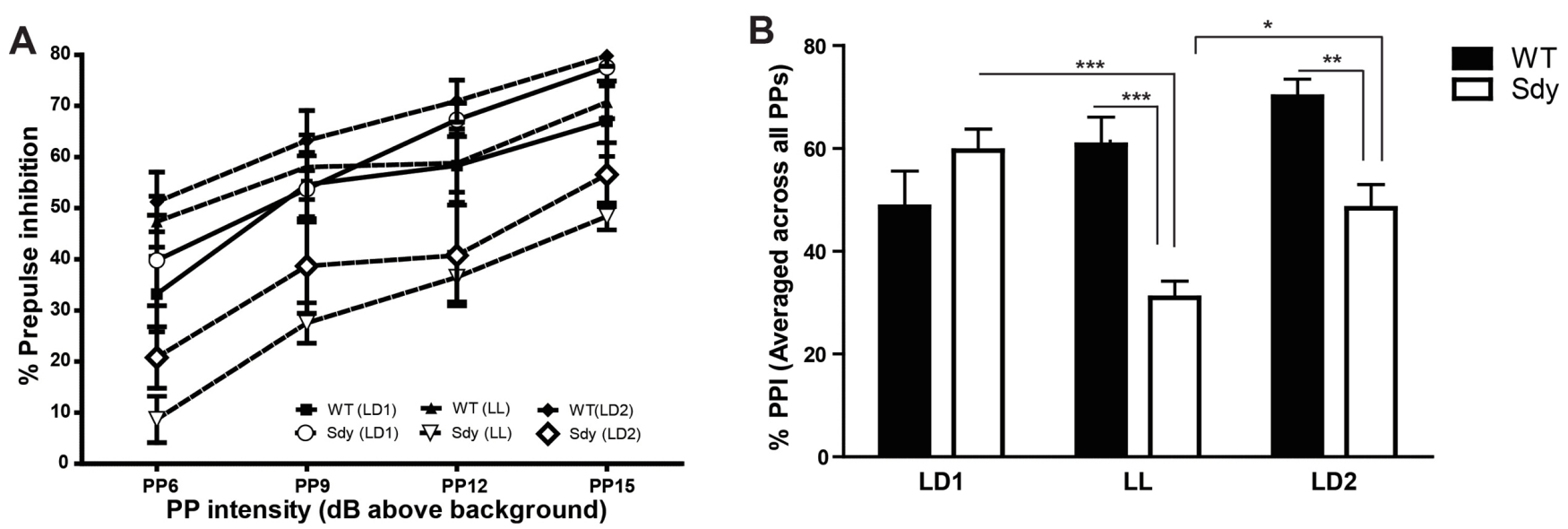
Figure 6

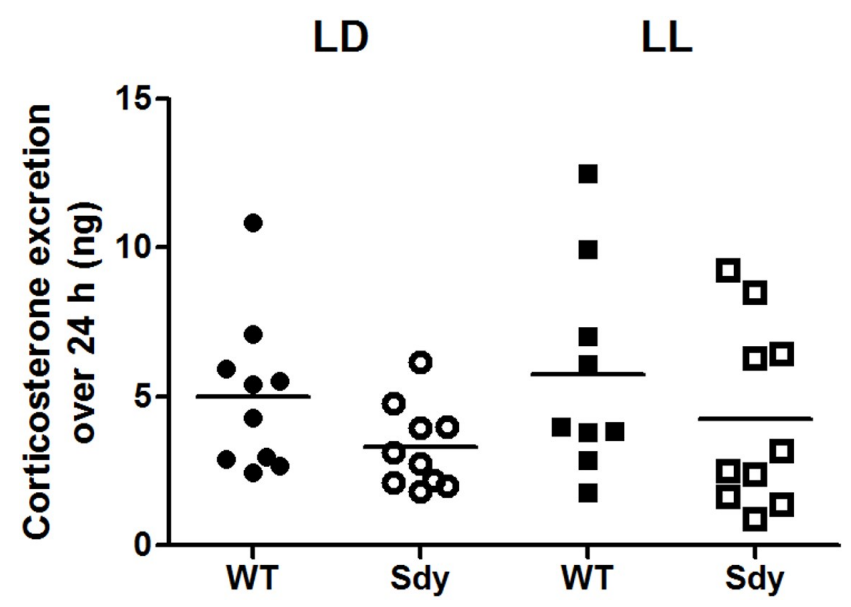


Table 1. Characterization of the running wheel activity of WT and Sandy mice under different lighting conditions.

\begin{tabular}{|c|c|c|c|c|c|c|c|c|c|}
\hline \multirow[t]{2}{*}{ Parameter $^{\text {a }}$} & \multicolumn{2}{|c|}{ Light:dark cycle } & \multicolumn{2}{|c|}{ Constant darkness } & \multicolumn{2}{|c|}{ Constant light } & \multicolumn{3}{|c|}{ Two-way ANOVA } \\
\hline & WT & Sdy & WT & Sdy & WT & Sdy & $\begin{array}{l}\text { Main effect } \\
\text { of Genotype }\end{array}$ & $\begin{array}{l}\text { Main effect } \\
\text { of Condition }\end{array}$ & Interaction \\
\hline Tau (h) & $24.0 \pm 0.01$ & $23.9 \pm 0.02$ & $23.8 \pm 0.03$ & $23.8 \pm 0.02$ & $24.9 \pm 0.09$ & $25.5 \pm 0.23$ & 0.017 & 0.000 & 0.0008 \\
\hline Alpha (h) & $12.4 \pm 0.16$ & $12.1 \pm 0.20$ & $13.6 \pm 0.32$ & $12.9 \pm 0.40$ & $10.0 \pm 0.89$ & $9.9 \pm 1.12$ & 0.470 & 0.000 & 0.8987 \\
\hline Total activity (wheel turns/24 h) & $8490 \pm 1337$ & $10400 \pm 2543$ & $7329 \pm 1171$ & $9617 \pm 2574$ & $3037 \pm 626$ & $6477 \pm 2191$ & 0.094 & 0.032 & 0.9096 \\
\hline Power of FFT & $0.05 \pm 0.007$ & $0.06 \pm 0.018$ & $0.04 \pm 0.009$ & $0.05 \pm 0.017$ & $0.04 \pm 0.01$ & $0.04 \pm 0.01$ & 0.475 & 0.457 & 0.9066 \\
\hline Activity day/night ratio & $0.1 \pm 0.034$ & $0.09 \pm 0.021$ & $0.09 \pm 0.035$ & $0.07 \pm 0.013$ & $0.1 \pm 0.02$ & $0.3 \pm 0.07$ & 0.052 & 0.000 & 0.0064 \\
\hline Variability of the activity onset (h) & $0.189 \pm 0.015$ & $0.336 \pm 0.043$ & $0.369 \pm 0.022$ & $0.520 \pm 0.065$ & $0.868 \pm 0.097$ & $1.491 \pm 0.092$ & 0.000 & 0.000 & 0.0003 \\
\hline Counts/bout of activity & $1279 \pm 279$ & $2014 \pm 864$ & $1309 \pm 358$ & $2240 \pm 1183$ & $814 \pm 230$ & $1662 \pm 703$ & 0.091 & 0.329 & 0.9583 \\
\hline Activity bout duration (min) & $47.4 \pm 6.4$ & $58.7 \pm 14.8$ & $54.9 \pm 8.8$ & $61.9 \pm 15.5$ & $45.6 \pm 10.1$ & $59.2 \pm 14.3$ & 0.234 & 0.186 & 0.9156 \\
\hline Bouts/day & $7.1 \pm 0.42$ & $6.6 \pm 0.61$ & $6.3 \pm 0.43$ & $6.2 \pm 0.52$ & $3.9 \pm 0.30$ & $4.5 \pm 0.52$ & 0.993 & 0.000 & 0.4388 \\
\hline Peak rate & $35.7 \pm 2.5$ & $37.8 \pm 3.9$ & $33.7 \pm 2.8$ & $38.6 \pm 5.1$ & $26.5 \pm 2.0$ & $31.8 \pm 4.9$ & 0.173 & 0.034 & 0.9062 \\
\hline Phase angle of activity onset & $-0.2 \pm 0.033$ & $-0.4 \pm 0.116$ & $\mathrm{n} / \mathrm{a}$ & $\mathrm{n} / \mathrm{a}$ & $\mathrm{n} / \mathrm{a}$ & $\mathrm{n} / \mathrm{a}$ & $\mathrm{n} / \mathrm{a}$ & $\mathrm{n} / \mathrm{a}$ & $\mathrm{n} / \mathrm{a}$ \\
\hline Phase angle of activity offset & $-0.6 \pm 0.171$ & $-0.6 \pm 0.119$ & $\mathrm{n} / \mathrm{a}$ & $\mathrm{n} / \mathrm{a}$ & $\mathrm{n} / \mathrm{a}$ & $\mathrm{n} / \mathrm{a}$ & $\mathrm{n} / \mathrm{a}$ & $\mathrm{n} / \mathrm{a}$ & $\mathrm{n} / \mathrm{a}$ \\
\hline
\end{tabular}

${ }^{a}$ Un description of the parameters can be found in the Material and methods section. The phase angles of activity onset and offset can

by definition only be measured under entrained conditions (e.g. a light:dark cycle). For this reason, it is not possible to do a two-way ANOVA for Genotype and Condition.

${ }^{\mathrm{b}}$ For the two-way ANOVA, the table presents the $\mathrm{p}$ values for the effects of Genotype and Condition and for the interaction.

WT, wild-type; Sdy, Sandy (Dtnbpl mutant); n/a, not applicable 